\title{
Overview of infections as an etiologic factor and complication in patients with vasculitides
}

\author{
Panagiotis Theofilis $^{1}$ (D) - Aikaterini Vordoni ${ }^{1}$ (D) $\cdot$ Maria Koukoulaki $^{1}$ (D) Georgios Vlachopanos $^{1}$ (D) \\ Rigas G. Kalaitzidis ${ }^{1}$ (D)
}

Received: 17 November 2021 / Accepted: 29 January 2022 / Published online: 14 February 2022

(c) The Author(s), under exclusive licence to Springer-Verlag GmbH Germany, part of Springer Nature 2022

\begin{abstract}
Vasculitides, a form of inflammatory autoimmune disease targeting the vessels, constitute an entity with significant morbidity and mortality. Infections have long been associated with vasculitides as a result of the incident immunosuppression following treatment induction and maintenance. Several microbial pathogens have been described as etiologic factors of infections in this patient population according to the type of vessels affected. Intense research has also been recently conducted in the interplay between vasculitides and certain viral infections, namely human immunodeficiency virus and severe acute respiratory syndrome coronavirus 2 . Of note, a plethora of scientific evidence is available regarding the role of infections as triggering factors for vasculitides. Among the main mechanisms implicated in this direction are the activation of $\mathrm{B}$ and $\mathrm{T}$ cells, the direct endothelial insult, the immune complex-mediated vascular injury, and the cell-mediated, type IV hypersensitivity vessel damage. Therefore, this review aims to summarize all the available evidence concerning this bidirectional interplay between infections and vasculitides.
\end{abstract}

Keywords Vasculitis · Infection · COVID-19 · HIV

\section{Introduction}

Vasculitides are a heterogeneous group of autoimmune diseases with great morbidity and mortality, characterized by fibrinoid necrosis and the presence of inflammatory leukocytes, leading to damage of the vessel wall [1]. Inflammation in this patient population leads to narrowing or even obstruction of the vessels resulting in reduced blood perfusion and the development of ischemic damage to the tissues and organs.

Both the size of the vessels and the organs affected are different between the different types of vasculitis and, therefore, their clinical manifestations vary [1]. Vasculitides may be pronominally classified into large-, medium-, and smallsized vessel vasculitides, as well as into primary or secondary vasculitides, including infectious or paraneoplastic vasculitides. In this review article, we first provide the latest evidence regarding the association between infections and vasculitides in an effort to increase awareness of the infectious etiology of vasculitis.

\section{Search strategy}

We performed a literature search in PubMed, Google Scholar, and Web of Science from inception till 15th January 2022, using the following keywords: vasculitis, infection, bacterial infection, viral infection, coronavirus disease-19, COVID-19, SARS-CoV-2, human immunodeficiency virus, HIV. Additionally, articles were extracted from the reference list of the retrieved articles if they were deemed relevant. Specifically, we focused our attention on papers published within the last 5 years.

Rigas G. Kalaitzidis

rigaska@gmail.com

Center for Nephrology “G. Papadakis”, General Hospital of Nikaia-Piraeus "Agios Panteleimon”, 18454 Piraeus, Nikaia, Greece 


\section{Evidence for the relationship between infections and vasculitis}

In the past, historical diseases such as tuberculosis or syphilitic aortitis have long been suspected to be triggering factors for many types of vasculitis [2].

Many different types of vasculitides may be associated with infections (Table 1). On the other hand, patients with vasculitis may develop infections, which sometimes mimic a relapse of the disease.

When an infection has been diagnosed in a patient with vasculitis, the subsequent question is to determine whether vasculitis is related or not to the infection and how to treat both conditions in the most appropriate and safest ways [10, $22,23]$. So far, a causal relationship between infection and vasculitis has only been established in a few instances, and the pathophysiologic mechanisms remain hypothetical [2].

\section{Type of vasculitis and different infectious agents involved}

In the small-vessel vasculitis, including ANCA-associated vasculitides (AAV) [24, 25] and/or small-vessel, immune complex-mediated vasculitis $[4,5,11]$, the possible role of infection in triggering de novo disease and relapse has been extensively investigated and a clear association has been demonstrated. On the other hand, there is only indirect evidence to support an infectious etiology for Kawasaki's disease, even though numerous organisms have been proposed but not proven [26].

In patients with granulomatosis with polyangiitis (GPA), $S$. aureus was the most commonly isolated organism in cultures from the upper airways that have been associated with an increased risk of relapse [24]. In light of this evidence, a cyclical pattern of GPA occurrence in cases of an infectious etiology is supported and is exhibited periodically with a maximum peak every 7.7 years [25].

Moreover, microscopic polyangiitis (MPA) is also associated with infections and environmental factors. It is suggested that infection is a major causal factor in the formation of ANCA. Importantly, substantial differentiation of glomerulonephritis due to infection and immune complex deposition versus ANCA-associated vasculitis could be easily performed with a kidney biopsy [6]. Indeed, different case reports have been described, whereby infective endocarditis caused by E. faecalis, Streptococcus, and Bartonella species were also related to ANCA vasculitis and markedly elevated levels of PR3-ANCA [6].

On the contrary, in the setting of eosinophilic granulomatosis with polyangiitis (EGPA), the majority of cases are idiopathic, associated with inhaled antigens rather than infections. Herein, vaccination and desensitization have been reported as triggering factors [27]. However, in EGPA the epidemiological data may be confounded by the severity of preceding asthma [28].

In IgA vasculitis-Henoch-Schonlein purpura (HSP), it is suggested that infections can trigger immune complex
Table 1 Microbial etiology for induction or exacerbation of vasculitis

\begin{tabular}{llll}
\hline Study & Mechanisms & Type of infection & Type of vasculitis \\
\hline Bacteria & Direct invasion & Mycobacterium TBC & Syphilitic aortitis \\
{$[3-9]$} & or & Non-TBC mycobacterial & GPA \\
& Immune complex-mediated & S. aureus & HSP \\
& & Streptococcus & Leukocytoclastic vasculitis \\
& & Gram-negative & Cutaneous vasculitis \\
& & Rickettsia & \\
Virus & Direct endothelial & Pseudomonas aeruginosa & \\
{$[10-16]$} & Invasion & HBV & PAN \\
& or & HCV & Cryoglobulinemic Vasculitis \\
& Indirect autoimmune mechanisms & HIV & HTLV-1 \\
& $\downarrow$ & Erythrovirus B19 & HSP \\
& by immunological factors & CMV & \\
& or & VZV & \\
by direct vascular injury & & Mycotic aneurism \\
Fungi & Direct invasion & & \\
or & Septic embolism & & Cutaneous \\
Parasites & Direct invasion & & Vasculitis \\
{$[18-21]$} & & Toxoplasmosis & \\
& & Trichinosis & \\
\hline
\end{tabular}

$T B C$ tuberculosis, GPA granulomatosis with polyangiitis, $H S P$ Henoch-Schonlein purpura, $H B V$ hepatitis $\mathrm{B}$ virus, $H C V$ hepatitis $\mathrm{C}$ virus, $H I V$ human immunodeficiency virus, $H T L V-1$ human T-cell lymphotropic virus type $1, P A N$ polyarteritis nodosa, $C M V$ cytomegalovirus, $V Z V$ varicella-zoster virus 
deposition. Although long-term observations are lacking, an interesting concept was presented as patients exhibited a constantly increased risk for serious infections during follow-up. Additionally, a higher rate of upper respiratory tract infections has been shown [3]. Concerning children with IgA vasculitis, specific inflammatory factors may be attributed and have a lasting effect on immune competence [4]. Another point of importance is that the incidence of IgA vasculitis exhibited seasonal increases in the spring and decreases in the winter, which may be related to a higher frequency of upper respiratory tract infections during the coldest months of the year. Interestingly, in the majority of patients with HSP there is an infection of the upper respiratory tract, indicative of a potential microbial etiology of the disease. Among children aged less than 10 years, $99.5 \%$ of cases suffer from either IgA vasculitis or Kawasaki disease, both exhibiting a seasonal pattern paralleling infections [29]. $\operatorname{Ig} \mathrm{A}$ vasculitis has also been associated with influenza infection [11].

Last but not least, leukocytoclastic vasculitis may also be a manifestation of bacterial infection [5]. Etiologically, the appearance of small-vessel cutaneous vasculitis is associated with drug reactions or certain viral or bacterial infections. Among patients with cutaneous vasculitis, beta-lactams, analgesics, or non-steroidal anti-inflammatory agents are common drugs associated with the disease, which usually have a good clinical outcome [30]. In leukocytoclastic vasculitis, the presence of upper respiratory tract infections shortly before the development of vasculitis was more common than in those with IgA vasculitis [5]. Cutaneous vasculitis has been described in patients with cystic fibrosis due to respiratory infections due to Pseudomonas aeruginosa, $S$. aureus, Haemophilus influenza, and Burkholderia cepacia complex [8, 31, 32]. Furthermore, a cutaneous small-vessel vasculitis may occur in childhood after an infection caused by the atypical bacterial pathogen Mycoplasma pneumoniae [33].

\section{Hepatitis B virus-associated polyarteritis nodosa}

Polyarteritis nodosa (PAN), a medium-vessel vasculitis, frequently results from hepatitis B virus infection (HBVPAN). HBV-PAN has become the most convincingly documented, immunologically-mediated, infection-associated systemic vasculitis and the single most important feature in confirming the diagnosis of PAN [13]. One of the highest rates reported comes from an area endemic for HBV infection and accounts for $30 \%$ to be HBV positive [34]. Control of the viral infection is mainly based on the use of antiviral drugs with the current availability of potent agents. Other rare cases of PAN have been associated with nontuberculous mycobacterial infection [14], with cutaneous polyarteritis nodosa occurrence in the setting of Mycobacterium tuberculosis infection also being described [35].

\section{Hepatitis C virus-associated cryoglobulinemic vasculitis}

Cryoglobulinemic vasculitis is the most frequent extrahepatic manifestation in patients infected with the hepatitis $\mathrm{C}$ virus (HCV) [10]. This causative relationship between hepatitis $\mathrm{C}$ and cryoglobulinemic vasculitis is well-established in more than $80 \%$ of the patients [12]. Its incidence has decreased over the past few decades, with direct-acting antivirals not always effective at eradicating or preventing the relapse of this complication despite achieving a sustained viral response [36-38].

\section{Human immunodeficiency Virus-associated vasculitides}

Human immunodeficiency virus (HIV) positive patients may also develop vasculitis, either mediated by immunological factors or by direct vascular injury, as well as by the restoration of protective pathogen-specific cellular immune response owing to the immune restoration inflammatory syndrome induced by antiretroviral treatment [39]. Hypersensitivity reactions should be considered as a possible etiology of vasculitis in HIV-infected patients [40]. HIV-associated PAN-like disease and Kawasaki-like syndrome have also been described, with significant differences when compared to the classic manifestations of PAN and Kawasaki disease, respectively [39]. Regarding large vessel vasculitis, it is more commonly encountered in HIV patients at an advanced disease stage, with multiple aneurysms and occlusions in less typical locations, sharing histologic similarities with Takayasu arteritis [41]. It should be noted that this large vessel vasculitis occurs independently of CD4 count and viral load, as well as in patients after starting antiviral therapy indicating the immune reconstitution inflammatory syndrome (IRIS) [42]. Physicians should be aware that vasculitis may have a heterogeneous presentation and can occur in association with HIV infection [15].

\section{Coronavirus disease-19-associated vasculitides}

The role of the recent severe acute respiratory syndrome coronavirus 2 (SARS-CoV-2), characterized by an inflammatory cytokine storm and incident endotheliitis [43, 44], in the pathogenesis of IgA-mediated vasculitis needs to be determined. Recently the occurrence of Henoch-Schonlein purpura secondary to a SARS-CoV-2 infection in children and adults was mentioned in several case reports [45]. Since SARS-CoV-2 causes a mucosal infection, the incident IL-6 production might be responsible for the 
stimulation of poor glycosylation/galactosylation of $\operatorname{Ig} \mathrm{A} 1$, leading to the formation of galactose-deficient $\operatorname{Ig} \mathrm{A} 1$, thus contributing to $\operatorname{IgA}$ vasculitis development and progression [46]. Case reports of AAV following coronavirus disease-19 (COVID-19) have also been described, presenting with renal involvement and contrasting prognosis [47]. Moreover, COVID-19 has been linked with the manifestation of other forms of vasculitis, such as Kawasaki disease and leukocytoclastic vasculitis [48-50]. SARS-CoV-2 may also lead to a small vessel vasculitis not involving the main coronaries [51]. Evidence of central nervous system vasculitis following COVID-19 was confirmed via biopsy despite a mild form of SARS-CoV-2 infection [52]. Gracia-Ramos et al. reviewed the available evidence on the incidence of autoimmune diseases in COVID-19 patients [53]. In incidence vasculitis patients, they noted a male sex predisposition, with the majority of patients exhibiting a mild-to-moderate COVID-19 disease course [53]. Vasculitis onset was reported approximately one month after SARS-CoV-2 infection and completely resolved in the vast majority of cases [53]. In a recently reported positron emission tomography/computed tomography study of recovered adult COVID-19 patients with residual symptoms, a higher target-to-blood pool ratio was observed in the thoracic aorta, right iliac artery, and femoral artery of COVID-19 patients compared to control, indicating a persistent vascular inflammation which could be responsible for vasculitic manifestations in the long-term recovery period [54]. AAV may as well be a complication of the Long-COVID-19 syndrome, with deleterious outcomes [55].

In children, Multisystem Inflammatory Syndrome (MIS-C) is a newly defined post-viral myocarditis inflammatory vasculopathy following COVID-19 infection [56], which can be complicated with giant coronary aneurysm formation [57]. Importantly, this syndrome differs in several aspects (epidemiology, clinical, and immunological findings) from Kawasaki disease [58]. This syndrome can also be found in adult patients (MIS-A), usually four months after the acute phase of COVID-19, presenting with multiorgan dysfunction frequently requiring intensive care unit admission, while a minority of patients may present with Kawasaki disease [59]. It should be stressed, however, that prompt immunomodulatory treatment may lead to the regression of myocardial injury and the reversibility of left ventricular dysfunction [60].

Further research in this field is required, however, to better define the pathophysiologic basis of autoimmune diseases incidence in COVID-19 [61]. It should also be stated that vaccination against SARS-CoV-2 may also be complicated with cutaneous vasculitic phenomena or even IgA vasculitis and AAV [62-66].

\section{Other virus-associated vasculitides}

Human T-cell lymphotropic virus type 1 (HTLV-1) has been shown to infect human endothelial cells and may explain the CNS vasculitis associated with the progressive spastic paraplegia seen with HTLV-1 infections [67]. Other viruses such as Erythrovirus B19, cytomegalovirus, and varicellazoster virus have also been reported to be associated with or implicated in the development of vasculitides [10]. Additionally, norovirus infection can precipitate the worsening of an underlying HSP vasculitis and lead to acute clinical decompensation [68].

\section{Fungal and parasitic disease-associated vasculitides}

Fungi diseases can also cause vasculitides. Herein, the proposed mechanism involves the direct invasion of blood vessels or septic embolization, leading to the well-known feature of 'mycotic aneurysm' [17]. It is noteworthy that various induction therapies in AAV also result in opportunistic fungal infections [69].

A plethora of parasitic diseases has been associated with vasculitis. Toxoplasmosis, trichinosis, strongyloidiasis, ascariasis, sarcocystosis, amoebiasis, leishmaniasis, and toxocariasis have been anecdotally reported in conjunction with vasculitis with cutaneous and/or systemic manifestations [18-21, 70].

\section{Mechanisms of infection-associated vasculitis}

Studies have provided valuable information on the mechanism of inflammation and innate immunity (Fig. 1). The mechanisms of infection-related vasculitis involve direct and indirect pathogen invasion. Direct pathogen invasion is detected within the blood vessel walls and is characterized by smooth muscle cell (SMC) accumulation, endothelial dysfunction, expression of reactive oxygen species (ROS), cytokines, chemokines, cellular adhesion molecules, and damage of the vessel wall [71]. It is also suggested that the pathogenesis of vasculitis differs according to the pathogenic organisms. The indirect mechanisms of infectionrelated vasculitis involve immune-mediated injury to the vessel walls, such as immune-complexes molecular mimicry, ANCAs, cytokines, superantigens, autoantigen complementarity, and T cell immune response [71].

\section{Activation of $T$ and $B$ cells}

Infections stimulate autoimmune responses with shared epitopes between pathogens and host, upregulated heat shock proteins, and stimulated lymphocytes [22]. Circulating 
Fig. 1 Mechanisms of interactions between infections and vasculitides consist of either a direct invasion of endothelial cells by the pathogen leading to vascular injury or indirectly by the activation of $\mathrm{T}$ and $\mathrm{B}$ cells, immune complex-mediated, or cell-mediated vessel damage

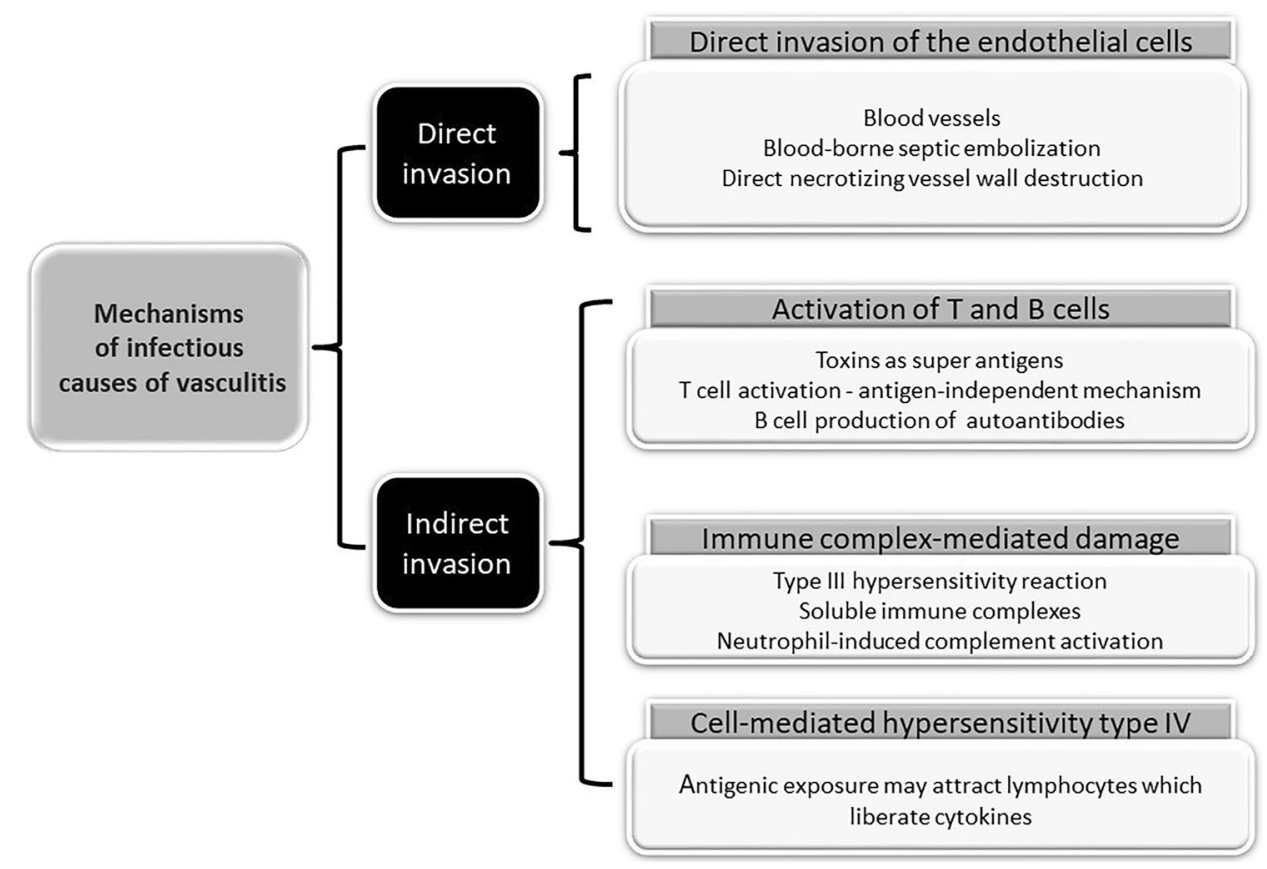

toxins often act as superantigens which are exotoxins produced by a small group of bacteria, primarily $S$. aureus and Streptococcus pyogenes [72]. These induce oligoclonal activation of $\mathrm{T}$ cells through an antigen-independent mechanism [73].

Superantigens also stimulate B cells to produce autoantibodies that may be involved in the pathogenesis of vasculitis (Fig. 2, Panel a) [22, 23]. The 'classic neutrophil pathway' has been described as a cause of necrotizing vasculitis and has been studied and confirmed by several groups. An additional 'T-cell pathway' has also been proposed, mainly causing granulomatous inflammation, promoting necrotizing vasculitis [74]. Infections are the starting point of both pathways and trigger the priming of neutrophils [74].

\section{Immune complex-mediated damage}

Immune complex-mediated damage represents a reaction of type III hypersensitivity where the antigens are the infectious agents or antigenic portions of them after the zone of equivalence is reached. The immune complexes precipitate and become trapped within vessel walls, stimulating an immune response (Fig. 2, Panel b) [75]. Type III hypersensitivity produces soluble immune complexes and, under certain conditions, may occasionally produce devastating tissue damage. A disease caused by soluble immune complexes may also be due to autoimmunity when the antigen involved is self-derived. Studies of circulating complement levels have shown a correlation with disease activity [75].

Defective handling of antigenic peptides, whether due to high antigenic load or abnormally functioning immune regulatory mechanisms, in chronic viral infections such as hepatitis $\mathrm{C}$ or hepatitis $\mathrm{B}$, might contribute to a state of persistent antigenemia, stimulation of an immune response with subsequent release of antigen-directed antibodies, and the formation of immune complexes. Subsequent complement activation generates the chemotactic factor $\mathrm{C} 5 \alpha$, which promotes the accumulation of circulating neutrophil and monocytes-macrophages [76]. It has been proposed that factors released by ANCA-activated neutrophils activate the alternative pathway of complement, resulting in enhanced recruitment and activation of neutrophils [77]. The alternative pathway is activated by a variety of cellular surfaces, including those of certain bacteria, viruses, fungi, and parasites. Sequential non-enzymatic protein-protein interactions among the terminal complement proteins initiated by C5a lead to the formation of the membrane attack complex (MAC). Because biological activities of C5a and MAC play a role in the pathogenesis of endothelial injury, this alternative pathway is now considered pathogenically important, and complement inhibitors (such as anti-C5a) may have efficacy in AAV, with $\mathrm{C} 5$ a potentially being an important therapeutic target [78]. Immunosuppressive therapy with glucocorticoids underpins current treatment for AAV. Agents targeting the complement system such as eculizumab, a monoclonal antibody that prevents the formation of C5a and C5b-9, and avacopan, a small molecule inhibitor of $\mathrm{C} 5 \mathrm{aR}$, may represent an alternative to steroids $[9,79]$.

Neutrophils are required for the development of bacteriaassociated vasculitides. They can sometimes be attributed to an antigen excess which in turn causes a rise in circulating immune complexes and inflammatory mediator deposition 


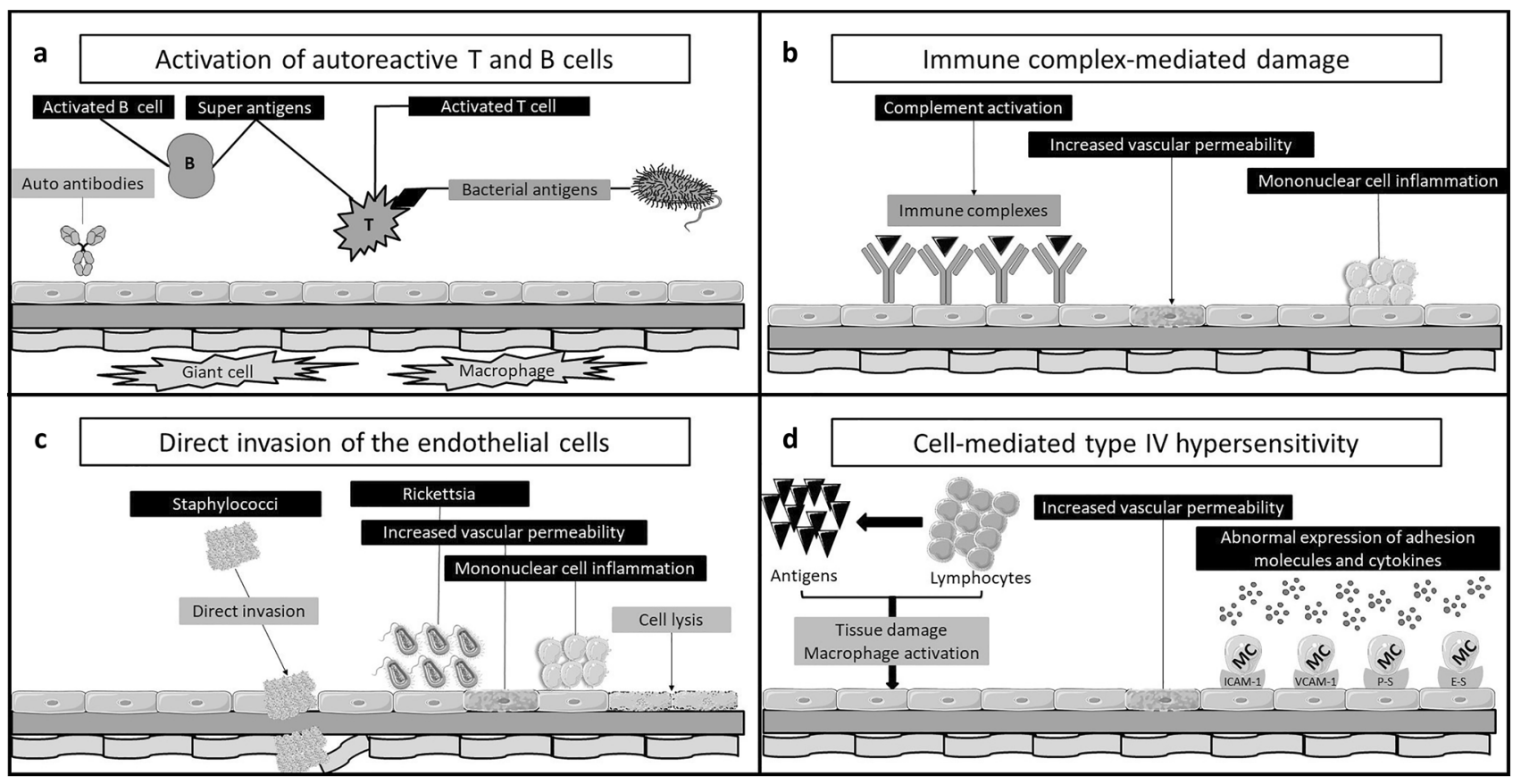

Fig. 2 Differential pathophysiologic pathways of infection-associated vasculitis. a Activated B cells, T cells, and superantigens in the setting of infection may lead to vessel injury. B Complement activation and the formation of immune complexes, a form of type III hypersensitivity, leads to increased vascular permeability and inflammation. c Endothelial cell invasion by bacteria could also promote endothelial dysfunction and vasculitis. d A cell-mediated, type IV hypersen-

within the vessel walls, with subsequent complement activation and blood vessel wall damage [75].

\section{Direct invasion of the endothelial cells}

Vasculitides following bacterial infections may occur from direct invasion of the endothelial cells as a result of an extension of a localized focus of infection affecting blood vessels or due to blood-borne septic embolization (Fig. 2, Panel c) [80].

Direct necrotizing vessel wall destruction can be induced by Pseudomonas aeruginosa or Legionella pneumophila in the lungs or Fusobacterium necrophorum in the internal jugular veins after pharyngitis [80]. In addition, fungi, protozoa, and helminths usually cause vasculitis through direct invasion of the vessel walls. Several bacteria, including Pseudomonas aeruginosa, S. aureus, Burkholderia cepacia, L. monocytogenes, and Haemophilus influenza, have been incriminated [6]. Direct endothelial cell invasion can also be the main pathogenic process in infections caused by CMV and herpes simplex virus [80]. A study reported that intracerebral varicella-zoster virus (VZV) antigens and DNA could be isolated from the walls of temporal arteries of a sitivity reaction with the attraction of lymphocytes to antigens may promote tissue damage and macrophage activation, with an abnormal expression of vascular adhesion molecules and cytokines. $M C$ monocyte, ICAM-1 intercellular adhesion molecule-1, VCAM-1 vascular cell adhesion molecule-1, $P$-S P-selectin, $E-S$ E-selectin, $T N F-\alpha$ tumor necrosis factor- $\alpha, I L$ interleukin

large proportion of patients affected with giant cell arteritis or aortitis [16].

\section{Cell-mediated hypersensitivity type IV}

Antigenic exposure may attract lymphocytes which liberate cytokines causing tissue damage and further activation of macrophages and lymphocytes (Fig. 2, Panel d) [81]. The abnormal expression of adhesion molecules and cytokines in vascular endothelium in most vasculitis syndromes as a manifestation of endothelial dysfunction can be triggered by a variety of stimuli, including infectious agents, immune complexes, and anti-endothelial cell antibodies [2].

\section{Infections in immunosuppressed patients with vasculitis}

The interest in infection-related vasculitides has been boosted over the last 2 decades by the development of new molecular techniques and the proof of true associations between viral infections and systemic vasculitis [82]. The aggressive treatment of vasculitis incurs a variety of adverse effects, among which infection is the most common and 
prevailed as a major complication in every stage of vasculitis. In long-term follow-up studies, the incidence of infection was approximately 30\% [7]. Most of the infections occurred during the first six months of vasculitis onset with high mortality [7]. Each type of vasculitis perhaps is associated with different infectious agents. Infections in vasculitides can be further divided into categories according to the infective agents: bacteria, fungi, and viruses [7].

Bacteria are the main infectious agents, accounting for $75.9 \%$ of all the cases [7, 22]. Gram-negative bacteria were the leading causative agents. Mixed infection was also noticeable. The distribution of infective sites includes primarily the lungs and the skin [7]. Opportunistic infections like Pneumocystis jirovecii pneumonia (PJP) occur early in the course of AAV, and it is frequently associated with the induction of immunosuppression [83]. However, PJP is not limited to the first six months following AAV diagnosis, and late-onset infection can occur in the context of augmented immunotherapy, particularly with concurrent lymphopenia [83]. It should be noted that AAV treatment with rituximab has been associated with a high frequency of bacterial infections in a recently reported meta-analysis [84]. At the same time, prophylaxis with trimethoprim-sulfamethoxazole may be associated with a lower risk of bacterial infections in this subgroup of patients [85].

\section{Risk factors for infections in vasculitides}

In a recent study, risk factors for infection in patients with vasculitis at the time of the diagnosis included age, smoking, kidney dysfunction, low CD4 counts, and cyclophosphamide (CYC) therapy [17]. Other factors associated with infection in patients with vasculitis included dialysis dependence, anemia, and hypoalbuminemia [7]. Interference with cell-mediated immunity, particularly with low CD4 counts, predisposes to infections [86]. Thus, close monitoring of lymphocyte counts could improve the prognosis of patients with vasculitis with regard to infection incidence [7]. It is now apparent that prophylaxis should be considered for other patients who are receiving intense immunosuppressive therapy, especially if they are lymphopenic or have a low CD4 count [69].

With regards to factors predisposing to a worse prognosis in patients with systemic vasculitis and COVID-19, important insight was provided by the latest retrospective cohort study (1202 patients), with $49.8 \%$ of patients requiring hospitalization [87]. Of the hospitalized patients, approximately $22 \%$ died. Poor COVID-19 outcomes were seen in older male subjects [87]. Moreover, the presence of an increasing number of comorbidities was related to an adverse COVID-19 prognosis, while at least moderate vasculitic disease activity and the intake of $10 \mathrm{mg} /$ day of prednisolone led to a higher odd of COVID-19 severity and mortality [87]. Moreover, the presence of comorbid respiratory disease might represent an additional risk factor, as shown by Rutherford et al. in a multicenter cohort of 65 patients with systemic vasculitis and COVID-19 [88].

\section{Immunosuppressive agents and infections in vasculitides}

The rate of severe infections and infection-related mortality in patients with severe vasculitis treated with immunosuppressive agent induction therapy was high. A recent metaanalysis including four studies and a total of 888 subjects estimated that in randomized controlled trials of necrotizing vasculitis, GPA, MPA, EGPA, and PAN treated with CYC combined with high dose glucocorticoids (GC) (mean cumulative doses of CYC were 2.7-50.4 g and of GC were 6-13 g), the risk of severe infection was $2.2 \%$, the risk of any infection was at $5.6 \%$, and an infection-related death was estimated at $1.7 \%$ per year per gram of CYC [23]. Interestingly, age, serum creatinine, and cumulative GC dose were not significantly associated with the rate of severe infections [23]. It is also suggested that oral CYC, which had a higher cumulative CYC dose compared to intravenous CYC, showed lower infection rates [89].

As far as rituximab therapy is concerned, a considerable percentage of patients with AAV may be susceptible to severe infections, with increasing age, impaired renal function, and lower body mass index acting as risk factors $[90,91]$. Dosing regimens (four-dose and two-dose) do not differ in the rate of incident infections [92]. In a recently reported Bayesian network meta-analysis of randomized controlled trials, mycophenolate mofetil was likely the safest treatment option with regard to severe infections in patients with AAV, followed by CYC, azathioprine, rituximab, and methotrexate [93]. The differences, however, were marginal and the only statistically significant comparison involved mycophenolate mofetil and methotrexate [93]. A combination of immunosuppressants (rituximab, CYC, GC) was not associated with a higher rate of severe infections in a cohort of patients with life-threatening AAV [94]. However, highdose GC added to rituximab may be related to a greater incidence of severe infections in a randomized clinical trial of patients with AAV but without severe glomerulonephritis or alveolar hemorrhage [95]. At the same time, the low-dose GC regimen was non-inferior regarding disease remission induction at six months [95].

\section{COVID-19 in patients with vasculitides}

The impact of SARS-CoV-2 infection and COVID-19 in patients with preexisting vasculitis also deserves an honorable mention. The presence of vasculitis was associated with 1.6-fold higher odds of hospitalization, while the use 
of disease-modifying anti-rheumatic drugs did not affect the need for hospitalization [96]. In the retrospective cohort study by Sattui et al. approximately $50 \%$ of patients required hospitalization and 15\% died [97]. Among the identified risk factors were the increased age, male sex, comorbidity burden, and high-dose glucocorticoids [97]. Similar risk factors were proposed by the results of the COVID-19 Global Rheumatology Alliance physician-reported registry of patients with rheumatic diseases and confirmed or suspected SARSCoV-2 infection, where the use of rituximab, sulfasalazine, and other immunosuppressants (azathioprine, cyclophosphamide, ciclosporin, mycophenolate, or tacrolimus) was additionally linked to increased death rates compared to methotrexate monotherapy [98]. Interestingly, the use of anti-tumor necrosis factor (TNF) agents was associated with a decreased odds of hospitalization [96]. Additionally, the use of the monoclonal antibody bamlanivimab was proven efficacious in a small cohort of patients with COVID-19 and AAV on rituximab therapy [99], a subgroup characterized by an impaired immune response to SARS-CoV-2 vaccination [100]. However, a booster dose may be met with greater success in these patients and is, therefore, warranted [101]. It is also worthwhile mentioning that vaccination against SARS$\mathrm{CoV}-2$ is well-tolerated and generally safe in patients with inflammatory rheumatic diseases, including vasculitides, with low rates of breakthrough infections [102]. However, disease relapses have been reported in patients with AAV and HSP [103, 104]. Finally, the impact of the pandemic in patients with vasculitides may be indirect through the interruption of immunosuppressive treatment, subsequently leading to increased rates of disease flares [105].

\section{Conclusions}

The relationship between infection and vasculitis is complex. Infections have long been suspected to be triggering factors for many types of vasculitides. A causal relationship has only been firmly established in a few instances using an epidemiological approach. Of great importance is the recognition of the infectious origin of vasculitides. Treatment strategies differ from those applied to non-infectious vasculitides. A high index of suspicion is required because clinical features are not always specific. Thus, an infection should always be excluded based on appropriate examinations, and, if confirmed, early and aggressive treatment should be administered. This accurate etiological diagnosis is important since immunosuppressive treatment may lead to further deterioration if an infection is the cause of vasculitis. Moreover, vasculitides and the need for immunosuppression represent a major risk factor for the development of common and opportunistic infections, including the highly prevalent SARS-CoV-2, which may additionally hinder the prognosis of these patients. Therefore, their prompt recognition and treatment are of utmost importance in this patient population to prevent excess morbidity and mortality.

Author contributions Panagiotis Theofilis: Design, drafted the work. Aikaterini Vordoni: Design, drafted the work. Maria Koukoulaki: Design, critically revised the work. Georgios Vlachopanos: Design, critically revised the work. Rigas G Kalaitzidis: Concept, design, drafted and critically revised the work. All authors approved the final manuscript as submitted and agree to be accountable for all aspects of the work.

Funding This research did not receive any specific grant from funding agencies in the public, commercial, or not-for-profit sectors.

Data availability Not applicable.

\section{Declarations}

Conflict of interest The authors declare that there is no conflict of interest relevant to the manuscript.

Research involving human participants and/or animals Not applicable.

Informed consent Not applicable.

\section{References}

1. Jennette JC (2013) Overview of the 2012 revised International Chapel Hill Consensus Conference nomenclature of vasculitides. Clin Exp Nephrol 17:603-606. https://doi.org/10.1007/ s10157-013-0869-6

2. Belizna CC, Hamidou MA, Levesque H, Guillevin L, Shoenfeld Y (2009) Infection and vasculitis. Rheumatology (Oxford) 48:475-482. https://doi.org/10.1093/rheumatology/kep026

3. Nossent JC, Raymond W, Keen H, Preen DB, Inderjeeth CA (2020) Infection rates before and after diagnosis of IgA vasculitis in childhood: a population-wide study using non-exposed matched controls. J Rheumatol 47:424-430. https://doi.org/10. 3899/jrheum. 190110

4. Nossent J, Raymond W, Keen H, Inderjeeth C, Preen D (2020) Long-term risk of comorbidity after IgA vasculitis in childhood: a population-based cohort study. Rheumatol Ther 7:927-935. https://doi.org/10.1007/s40744-020-00239-y

5. Garcia-Porrua C, Gonzalez-Gay MA (1999) Bacterial infection presenting as cutaneous vasculitis in adults. Clin Exp Rheumatol $17: 471-473$

6. Cervi A, Kelly D, Alexopoulou I, Khalidi N (2017) ANCA-associated pauci-immune glomerulonephritis in a patient with bacterial endocarditis: a challenging clinical dilemma. Clin Nephrol Case Stud 5:32-37. https://doi.org/10.5414/CNCS109076

7. Ribi C, Cohen P, Pagnoux C, Mahr A, Arene JP, Puechal X, Carli P, Kyndt X, Le Hello C, Letellier P, Cordier JF, Guillevin L, French Vasculitis Study G (2010) Treatment of polyarteritis nodosa and microscopic polyangiitis without poor-prognosis factors: a prospective randomized study of one hundred twenty-four patients. Arthritis Rheum 62:1186-1197. https://doi.org/10.1002/ art. 27340

8. Kayria M, Chris O, Dhasmana DJ, Nilesh M, Hodson ME, Khin G, Diana B, Simmonds NJ (2017) Burkholderia cepacia 
complex and limited cutaneous vasculitis in patients with cystic fibrosis: a case series. JRSM Open 8:2054270417692732. https://doi.org/10.1177/2054270417692732

9. Gadela NV, Drekolias D, Rizkallah A, Jacob J (2020) Infective endocarditis: a rare trigger of immunoglobulin a vasculitis in an adult. Cureus 12:e9892. https://doi.org/10.7759/cureus.9892

10. Pagnoux C, Cohen P, Guillevin L (2006) Vasculitides secondary to infections. Clin Exp Rheumatol 24:S71-81

11. Farhadian JA, Castilla C, Shvartsbeyn M, Meehan SA, Neimann A, Pomeranz MK (2015) IgA vasculitis (Henoch-Schonlein purpura). Dermatol Online J. https://doi.org/10.5070/ D32112029544

12. Agnello V, Chung RT, Kaplan LM (1992) A role for hepatitis $\mathrm{C}$ virus infection in type II cryoglobulinemia. N Engl J Med 327:1490-1495. https://doi.org/10.1056/NEJM19921119327 2104

13. Cacoub P, Terrier B (2009) Hepatitis B-related autoimmune manifestations. Rheum Dis Clin N Am 35:125-137. https:// doi.org/10.1016/j.rdc.2009.03.006

14. Lian SB, Teoh YL, Tay YK (2019) A rare case of polyarteritis nodosa associated with nontuberculous mycobacterial infection. Clin Case Rep 7:1982-1983. https://doi.org/10.1002/ccr3. 2414

15. Manuel A, Victorio T, Gomes C, Martins T, Dias Neto A (2015) Vasculitis: an unusual manifestation in an HIV-infected patient. Braz J Infect Dis 19:439-441. https://doi.org/10.1016/j.bjid. 2015.04.006

16. Gilden D, Nagel MA (2016) Varicella zoster virus triggers the immunopathology of giant cell arteritis. Curr Opin Rheumatol 28:376-382. https://doi.org/10.1097/BOR.0000000000000292

17. Yang L, Xie H, Liu Z, Chen Y, Wang J, Zhang H, Ge Y, Hu W (2018) Risk factors for infectious complications of ANCA-associated vasculitis: a cohort study. BMC Nephrol 19:138. https:// doi.org/10.1186/s12882-018-0933-2

18. Ohta T, Imanaga H, Oku S, Kusumoto H, Sugio Y, Tamiya S, Kubo Y, Ogawa R, Hikosaka K, Norose K, Ohno Y (2019) Toxoplasmosis-associated central nervous system vasculitis accompanied by multiple cerebral hemorrhages developing subsequent to cord blood transplantation. Rinsho Ketsueki 60:118-123. https:// doi.org/10.11406/rinketsu.60.118

19. Renner R, Fleck A, Schubert S, Baerwald RC, Beer J, Schober R, Holl-Ulrich K, Sticherling M (2008) Chronic urticaria and angioedema with concomitant eosinophilic vasculitis due to Trichinella infection. Acta Derm Venereol 88:78-79. https://doi.org/ 10.2340/00015555-0331

20. de Boysson H, Martin Silva N, Comoz F, Boutemy J, Bienvenu B (2015) Vasculitis secondary to anti-C1q antibodies induced by toxocariasis. Infection 43:755-758. https://doi.org/10.1007/ s15010-015-0766-x

21. Sapia EY, Lascano MF, Aboud G, Bendersky T, Moscatelli G, Dastugue M, Altcheh J (2020) Visceral larva migrans: a pediatric case of atypical presentation with cutaneous vasculitis in the province of Buenos Aires, Argentina. Arch Argent Pediatr 118:e313-e316. https://doi.org/10.5546/aap.2020.e313

22. Mohan N, Kerr G (2003) Infectious etiology of vasculitis: diagnosis and management. Curr Rheumatol Rep 5:136-141. https:// doi.org/10.1007/s11926-003-0041-5

23. Jung M, Barra L (2018) Rate of infections in severe necrotising vasculitis patients treated with cyclophosphamide induction therapy: a meta-analysis. Clin Exp Rheumatol 36(Suppl 111):129-134

24. Stegeman CA, Tervaert JW, de Jong PE, Kallenberg CG (1996) Trimethoprim-sulfamethoxazole (co-trimoxazole) for the prevention of relapses of Wegener's granulomatosis. Dutch Co-Trimoxazole Wegener Study Group. N Engl J Med 335:16-20. https:// doi.org/10.1056/NEJM199607043350103
25. Watts RA, Mooney J, Skinner J, Scott DG, Macgregor AJ (2012) The contrasting epidemiology of granulomatosis with polyangiitis (Wegener's) and microscopic polyangiitis. Rheumatology (Oxford) 51:926-931. https://doi.org/10.1093/rheumatology/ ker454

26. Burgner D, Harnden A (2005) Kawasaki disease: what is the epidemiology telling us about the etiology? Int J Infect Dis 9:185-194. https://doi.org/10.1016/j.ijid.2005.03.002

27. Guillevin L, Cohen P, Gayraud M, Lhote F, Jarrousse B, Casassus $\mathrm{P}$ (1999) Churg-Strauss syndrome. Clinical study and long-term follow-up of 96 patients. Medicine (Baltimore) 78:26-37. https:// doi.org/10.1097/00005792-199901000-00003

28. Hauser T, Mahr A, Metzler C, Coste J, Sommerstein R, Gross WL, Guillevin L, Hellmich B (2008) The leucotriene receptor antagonist montelukast and the risk of Churg-Strauss syndrome: a case-crossover study. Thorax 63:677-682. https://doi.org/10. 1136/thx.2007.087825

29. Mossberg M, Segelmark M, Kahn R, Englund M, Mohammad AJ (2018) Epidemiology of primary systemic vasculitis in children: a population-based study from southern Sweden. Scand J Rheumatol 47:295-302. https://doi.org/10.1080/03009742.2017. 1412497

30. Garcia-Porrua C, Gonzalez-Gay MA, Lopez-Lazaro L (1999) Drug associated cutaneous vasculitis in adults in northwestern Spain. J Rheumatol 26:1942-1944

31. Bernstein ML, McCusker MM, Grant-Kels JM (2008) Cutaneous manifestations of cystic fibrosis. Pediatr Dermatol 25:150-157. https://doi.org/10.1111/j.1525-1470.2008.00620.x

32. Klimko A, Brandt A, Brustan MI, Balgradean M (2020) A case report of cystic fibrosis complicated by Burkholderia cepacia and cutaneous vasculitis. Cureus 12:e8158. https://doi.org/10.7759/ cureus. 8158

33. Betti C, Camozzi P, Gennaro V, Bianchetti MG, Scoglio M, Simonetti GD, Milani GP, Lava SAG, Ferrarini A (2021) Atypical bacterial pathogens and small-vessel leukocytoclastic vasculitis of the skin in children: systematic literature review. Pathogens. https://doi.org/10.3390/pathogens 10010031

34. Mahr A, Guillevin L, Poissonnet M, Ayme S (2004) Prevalences of polyarteritis nodosa, microscopic polyangiitis, Wegener's granulomatosis, and Churg-Strauss syndrome in a French urban multiethnic population in 2000: a capture-recapture estimate. Arthritis Rheum 51:92-99. https://doi.org/10.1002/art.20077

35. Imanishi H, Tsuruta D, Oshimo T, Sowa J, Mizuno N, Nakagawa K, Ishii M (2012) Cutaneous polyarteritis nodosa induced by Mycobacterium tuberculosis. J Dermatol 39:738-739. https:// doi.org/10.1111/j.1346-8138.2011.01398.x

36. Stubbs A, Kowal C, Askari A, Anthony DD, Mattar M (2018) Achieving sustained viral remission in patients with chronic $\mathrm{HCV}$ infection and cryoglobulinemic vasculitis does not always correlate with normalization of the serologic markers. J Clin Cell Immunol 9:562. https://doi.org/10.4172/2155-9899.1000562

37. Zignego AL, Marri S, Gragnani L (2021) Impact of direct acting antivirals on hepatitis c virus-related cryoglobulinemic syndrome. Minerva Gastroenterol (Torino). https://doi.org/10. 23736/S2724-5985.21.02848-8

38. Mazzaro C, Mauro E, Ermacora A, Doretto P, Fumagalli S, Tonizzo M, Toffolutti F, Gattei V (2021) Hepatitis C virusrelated cryoglobulinemic vasculitis. Minerva Med 112:175-187. https://doi.org/10.23736/S0026-4806.20.07120-7

39. Vega LE, Espinoza LR (2020) Vasculitides in HIV infection. Curr Rheumatol Rep 22:60. https://doi.org/10.1007/ s11926-020-00945-0

40. Bennett BS, Mikaberidze N, Ahmadi LM (2019) A case of dolutegravir-induced cutaneous small vessel vasculitis. AIDS 33:1803-1804. https://doi.org/10.1097/QAD.0000000000 002262 
41. Pillay B, Ramdial PK, Naidoo DP (2015) HIV-associated largevessel vasculopathy: a review of the current and emerging clinicopathological spectrum in vascular surgical practice. Cardiovasc J Afr 26:70-81. https://doi.org/10.5830/CVJA-2015-017

42. Ferfar Y, Savey L, Comarmond C, Sadaghianloo N, Garrido M, Domont F, Valantin MA, Pourcher-Martinez V, Cluzel P, Fouret P, Chiche L, Gaudric J, Koskas F, Cacoub P, Saadoun D (2018) Large-vessel vasculitis in human immunodeficiency virus-infected patients. J Vasc Surg 67:1501-1511. https://doi. org/10.1016/j.jvs.2017.08.099

43. Theofilis P, Sagris M, Oikonomou E, Antonopoulos AS, Siasos G, Tsioufis C, Tousoulis D (2021) Inflammatory mechanisms contributing to endothelial dysfunction. Biomedicines. https:// doi.org/10.3390/biomedicines9070781

44. Sagris M, Theofilis P, Antonopoulos AS, Tsioufis C, Oikonomou E, Antoniades C, Crea F, Kaski JC, Tousoulis D (2021) Inflammatory mechanisms in COVID-19 and atherosclerosis: current pharmaceutical perspectives. Int J Mol Sci. https://doi.org/10. 3390/ijms 22126607

45. Farooq H, Aemaz Ur Rehman M, Asmar A, Asif S, Mushtaq A, Qureshi MA (2021) The pathogenesis of COVID-19-induced IgA nephropathy and IgA vasculitis: a systematic review. J Taibah Univ Med Sci. https://doi.org/10.1016/j.jtumed.2021.08.012

46. Heineke MH, Ballering AV, Jamin A, Ben Mkaddem S, Monteiro RC, Van Egmond M (2017) New insights in the pathogenesis of immunoglobulin A vasculitis (Henoch-Schonlein purpura). Autoimmun Rev 16:1246-1253. https://doi.org/10.1016/j.autrev. 2017.10.009

47. Izci Duran T, Turkmen E, Dilek M, Sayarlioglu H, Arik N (2021) ANCA-associated vasculitis after COVID-19. Rheumatol Int 41:1523-1529. https://doi.org/10.1007/s00296-021-04914-3

48. Camprodon Gomez M, Gonzalez-Cruz C, Ferrer B, Barbera MJ (2020) Leucocytoclastic vasculitis in a patient with COVID-19 with positive SARS-CoV-2 PCR in skin biopsy. BMJ Case Rep. https://doi.org/10.1136/bcr-2020-238039

49. Jiao FY (2020) Kawasaki disease: a new manifestation of COVID-19 in children. Zhongguo Dang Dai Er Ke Za Zhi 22:677-678

50. Kumar G, Pillai S, Norwick P, Bukulmez H (2021) Leucocytoclastic vasculitis secondary to COVID-19 infection in a young child. BMJ Case Rep. https://doi.org/10.1136/bcr-2021-242192

51. Maccio U, Zinkernagel AS, Shambat SM, Zeng X, Cathomas G, Ruschitzka F, Schuepbach RA, Moch H, Varga Z (2021) SARS-CoV-2 leads to a small vessel endotheliitis in the heart. EBioMedicine 63:103182. https://doi.org/10.1016/j.ebiom.2020. 103182

52. Timmons GM, Rempe T, Bevins EA, Goodwill V, Miner A, Kavanaugh A, Ritter M, Graves JS (2021) CNS lymphocytic vasculitis in a young woman with COVID-19 infection. Neurol Neuroimmunol Neuroinflamm. https://doi.org/10.1212/NXI. 0000000000001048

53. Gracia-Ramos AE, Martin-Nares E, Hernandez-Molina G (2021) New onset of autoimmune diseases following COVID-19 diagnosis. Cells. https://doi.org/10.3390/cells10123592

54. Sollini M, Ciccarelli M, Cecconi M, Aghemo A, Morelli P, Gelardi F, Chiti A (2021) Vasculitis changes in COVID-19 survivors with persistent symptoms: an [(18)F]FDG-PET/CT study. Eur J Nucl Med Mol Imaging 48:1460-1466. https://doi.org/10. 1007/s00259-020-05084-3

55. Morris D, Patel K, Rahimi O, Sanyurah O, Iardino A, Khan N (2021) ANCA vasculitis: a manifestation of post-COVID-19 syndrome. Respir Med Case Rep 34:101549. https://doi.org/10. 1016/j.rmcr.2021.101549

56. McMurray JC, May JW, Cunningham MW, Jones OY (2020) Multisystem inflammatory syndrome in children (MIS-C), a postviral myocarditis and systemic vasculitis-a critical review of its pathogenesis and treatment. Front Pediatr 8:626182. https://doi. org/10.3389/fped.2020.626182

57. Villacis-Nunez DS, Hashemi S, Nelson MC, Flanagan E, Thakral A, Rodriguez F 3rd, Jaggi P, Oster ME, Prahalad S, RousterStevens KA (2021) Giant coronary aneurysms in multisystem inflammatory syndrome in children associated with SARSCoV-2 infection. JACC Case Rep 3:1499-1508. https://doi.org/ 10.1016/j.jaccas.2021.06.043

58. Sharma C, Ganigara M, Galeotti C, Burns J, Berganza FM, Hayes DA, Singh-Grewal D, Bharath S, Sajjan S, Bayry J (2021) Multisystem inflammatory syndrome in children and Kawasaki disease: a critical comparison. Nat Rev Rheumatol 17:731-748. https://doi.org/10.1038/s41584-021-00709-9

59. Patel P, DeCuir J, Abrams J, Campbell AP, Godfred-Cato S, Belay ED (2021) Clinical characteristics of multisystem inflammatory syndrome in adults: a systematic review. JAMA Netw Open 4:e2126456. https://doi.org/10.1001/jamanetworkopen. 2021.26456

60. Fabi M, Filice E, Biagi C, Andreozzi L, Palleri D, Mattesini BE, Rizzello A, Gabrielli L, Ghizzi C, Di Luca D, Caramelli F, De Fanti A, Lanari M (2021) Multisystem inflammatory syndrome following SARS-CoV-2 infection in children: one year after the onset of the pandemic in a high-incidence area. Viruses. https:// doi.org/10.3390/v13102022

61. Tang KT, Hsu BC, Chen DY (2021) Autoimmune and rheumatic manifestations associated with COVID-19 in adults: an updated systematic review. Front Immunol 12:645013. https://doi.org/10. 3389/fimmu.2021.645013

62. Cavalli G, Colafrancesco S, De Luca G, Rizzo N, Priori R, Conti F, Dagna L (2021) Cutaneous vasculitis following COVID-19 vaccination. Lancet Rheumatol 3:e743-e744. https://doi.org/10. 1016/S2665-9913(21)00309-X

63. Kharkar V, Vishwanath T, Mahajan S, Joshi R, Gole P (2021) Asymmetrical cutaneous vasculitis following COVID-19 vaccination with unusual eosinophil preponderance. Clin Exp Dermatol. https://doi.org/10.1111/ced.14797

64. Fiorillo G, Pancetti S, Cortese A, Toso F, Manara S, Costanzo A, Borroni RG (2021) Leukocytoclastic vasculitis (cutaneous small-vessel vasculitis) after COVID-19 vaccination. J Autoimmun 127:102783. https://doi.org/10.1016/j.jaut.2021.102783

65. Mohamed MMB, Wickman TJ, Fogo AB, Velez JCQ (2021) De novo immunoglobulin a vasculitis following exposure to SARSCoV-2 immunization. Ochsner J 21:395-401. https://doi.org/10. 31486/toj.21.0083

66. Feghali EJ, Zafar M, Abid S, Santoriello D, Mehta S (2021) Denovo antineutrophil cytoplasmic antibody-associated vasculitis following the mRNA-1273 (Moderna) vaccine for COVID-19. Cureus 13:e19616. https://doi.org/10.7759/cureus.19616

67. Vernant JC, Smadja D, Deforge-Lasseur C, Cabre P, Buisson G, Neisson-Vernant C, Desgranges C (1994) Vasculitis and neurologic manifestations related to HTLV-1. Presse Med 23:1421-1425

68. McLaughlin SK, Lawrence L, Adler J, Mehta H (2020) HenochSchonlein purpura-associated hemorrhagic shock after secondary norovirus infection. Cureus 12:e11653. https://doi.org/10.7759/ cureus. 11653

69. Wolfe RM, Peacock JE Jr (2017) Pneumocystis pneumonia and the rheumatologist: which patients are at risk and how can PCP be prevented? Curr Rheumatol Rep 19:35. https://doi.org/10. 1007/s11926-017-0664-6

70. Lhote F (2004) Systemic vasculitis during parasitosis. Presse Med 33:1389-1401. https://doi.org/10.1016/s0755-4982(04) 98938-5

71. Rodriguez-Pla A, Stone JH (2006) Vasculitis and systemic infections. Curr Opin Rheumatol 18:39-47. https://doi.org/10.1097/ 01.bor.0000197999.58073.2e 
72. Manders SM (1998) Toxin-mediated streptococcal and staphylococcal disease. J Am Acad Dermatol 39:383-398. https://doi. org/10.1016/s0190-9622(98)70314-7

73. Xu SX, McCormick JK (2012) Staphylococcal superantigens in colonization and disease. Front Cell Infect Microbiol 2:52. https://doi.org/10.3389/fcimb.2012.00052

74. Wilde B, van Paassen P, Witzke O, Tervaert JWC (2011) New pathophysiological insights and treatment of ANCA-associated vasculitis. Kidney Int 79:599-612. https://doi.org/10.1038/ki. 2010.472

75. Millikan LE, Flynn TC (1999) Infectious etiologies of cutaneous vasculitis. Clin Dermatol 17:509-514. https://doi.org/10. 1016/s0738-081x(99)00061-9

76. Couser WG (2012) Basic and translational concepts of immune-mediated glomerular diseases. J Am Soc Nephrol 23:381-399. https://doi.org/10.1681/ASN.2011030304

77. Xiao H, Schreiber A, Heeringa P, Falk RJ, Jennette JC (2007) Alternative complement pathway in the pathogenesis of disease mediated by anti-neutrophil cytoplasmic autoantibodies. Am J Pathol 170:52-64. https://doi.org/10.2353/ajpath.2007.060573

78. Wu EY, McInnis EA, Boyer-Suavet S, Mendoza CE, Aybar LT, Kennedy KB, Poulton CJ, Henderson CD, Hu Y, Hogan SL, Hu P, Xiao H, Nachman PH, Jennette JC, Falk RJ, Bunch DO (2019) Measuring circulating complement activation products in myeloperoxidase- and proteinase 3-antineutrophil cytoplasmic antibody-associated vasculitis. Arthritis Rheumatol 71:1894-1903. https://doi.org/10.1002/art.41011

79. Onuora S (2021) Avacopan offers alternative to steroids for ANCA-associated vasculitis. Nat Rev Rheumatol 17:249. https://doi.org/10.1038/s41584-021-00615-0

80. Witort-Serraglini E, Del Rosso M, Lotti TM, Matucci-Cerinic M (1999) Endothelial injury in vasculitides. Clin Dermatol 17:587-590. https://doi.org/10.1016/s0738-081x(99)00079-6

81. Weyand CM, Goronzy JJ (2014) Giant-cell arteritis and polymyalgia rheumatica. N Engl J Med 371:1653. https://doi.org/ 10.1056/NEJMc1409206

82. Thomas K, Vassilopoulos D (2017) Infections and vasculitis. Curr Opin Rheumatol 29:17-23. https://doi.org/10.1097/BOR. 0000000000000348

83. Matraiah EH, Olisaka N, Philipos M, Walbaum D, Dospinescu P, Fluck N, Basu N, Kidder D (2018) Late-onset Pneumocystis jirovecii pneumonia (PJP) in patients with ANCA-associated vasculitis. Clin Rheumatol 37:1991-1996. https://doi.org/10. 1007/s10067-018-4155-6

84. Thery-Casari C, Euvrard R, Mainbourg S, Durupt S, Reynaud Q, Durieu I, Belot A, Lobbes H, Cabrera N, Lega JC (2020) Severe infections in patients with anti-neutrophil cytoplasmic antibody-associated vasculitides receiving rituximab: a metaanalysis. Autoimmun Rev 19:102505. https://doi.org/10.1016/j. autrev.2020.102505

85. Kronbichler A, Kerschbaum J, Gopaluni S, Tieu J, Alberici F, Jones RB, Smith RM, Jayne DRW (2018) Trimethoprimsulfamethoxazole prophylaxis prevents severe/life-threatening infections following rituximab in antineutrophil cytoplasm antibody-associated vasculitis. Ann Rheum Dis 77:1440-1447. https://doi.org/10.1136/annrheumdis-2017-212861

86. Morris A, Norris KA (2012) Colonization by Pneumocystis jirovecii and its role in disease. Clin Microbiol Rev 25:297317. https://doi.org/10.1128/CMR.00013-12

87. Sattui SE, Conway R, Putman MS, Seet AM, Gianfrancesco MA, Beins K, Hill C, Liew D, Mackie SL, Mehta P (2021) Outcomes of COVID-19 in patients with primary systemic vasculitis or polymyalgia rheumatica from the COVID-19 Global Rheumatology Alliance physician registry: a retrospective cohort study. Lancet Rheumatol. https://doi.org/10.1016/ S2665-9913(21)00316-7
88. Rutherford MA, Scott J, Karabayas M, Antonelou M, Gopaluni S, Gray D, Barrett J, Brix SR, Dhaun N, McAdoo SP, Smith RM, Geddes CC, Jayne D, Luqmani R, Salama AD, Little MA, Basu N, Uk IV, Rare Disease G (2021) Risk factors for severe outcomes in patients with systemic vasculitis and COVID-19: a binational, registry-based cohort study. Arthritis Rheumatol 73:1713-1719. https://doi.org/10.1002/art.41728

89. Adu D, Pall A, Luqmani RA, Richards NT, Howie AJ, Emery P, Michael J, Savage CO, Bacon PA (1997) Controlled trial of pulse versus continuous prednisolone and cyclophosphamide in the treatment of systemic vasculitis. QJM 90:401-409. https:// doi.org/10.1093/qjmed/90.6.401

90. Segelmark L, Flores-Suarez L, Mohammad A (2021) Severe infections in patients with ANCA-associated vasculitis treated with rituximab. Rheumatology (Oxford) 61:205-212. https://doi. org/10.1093/rheumatology/keab293

91. Odler B, Windpessl M, Krall M, Steiner M, Riedl R, Hebesberger C, Ursli M, Zitt E, Lhotta K, Antlanger M, Cejka D, Gauckler P, Wiesholzer M, Saemann M, Rosenkranz AR, Eller K, Kronbichler A (2021) The risk of severe infections following rituximab administration in patients with autoimmune kidney diseases: Austrian ABCDE registry analysis. Front Immunol 12:760708. https://doi.org/10.3389/fimmu.2021.760708

92. Benard V, Farhat C, Zarandi-Nowroozi M, Durand M, Charles P, Puechal X, Guillevin L, Pagnoux C, Makhzoum JP (2021) Comparison of two rituximab induction regimens for antineutrophil cytoplasm antibody-associated vasculitis: systematic review and meta-analysis. ACR Open Rheumatol 3:484-494. https://doi.org/ 10.1002/acr2.11274

93. Lee YH, Song GG (2021) Comparative efficacy and safety of rituximab, mycophenolate, methotrexate, and cyclophosphamide versus azathioprine as maintenance therapy in antineutrophil cytoplasmic antibody-associated vasculitis: a Bayesian network meta-analysis of randomized controlled trials. Int J Clin Pharmacol Ther. https://doi.org/10.5414/CP204053

94. Gulati K, Edwards H, Prendecki M, Cairns TD, Condon M, Galliford J, Griffith M, Levy JB, Tam FWK, Tanna A, Pusey CD, McAdoo SP (2021) Combination treatment with rituximab, lowdose cyclophosphamide and plasma exchange for severe antineutrophil cytoplasmic antibody-associated vasculitis. Kidney Int 100:1316-1324. https://doi.org/10.1016/j.kint.2021.08.025

95. Furuta S, Nakagomi D, Kobayashi Y, Hiraguri M, Sugiyama T, Amano K, Umibe T, Kono H, Kurasawa K, Kita Y, Matsumura R, Kaneko Y, Ninagawa K, Hiromura K, Kagami SI, Inaba Y, Hanaoka H, Ikeda K, Nakajima H, Lo VASC (2021) Effect of reduced-dose vs high-dose glucocorticoids added to rituximab on remission induction in ANCA-associated vasculitis: a randomized clinical trial. JAMA 325:2178-2187. https://doi.org/10. 1001/jama.2021.6615

96. Gianfrancesco M, Hyrich KL, Al-Adely S, Carmona L, Danila MI, Gossec L, Izadi Z, Jacobsohn L, Katz P, Lawson-Tovey S, Mateus EF, Rush S, Schmajuk G, Simard J, Strangfeld A, Trupin L, Wysham KD, Bhana S, Costello W, Grainger R, Hausmann JS, Liew JW, Sirotich E, Sufka P, Wallace ZS, Yazdany J, Machado PM, Robinson PC, Alliance C-GR (2020) Characteristics associated with hospitalisation for COVID-19 in people with rheumatic disease: data from the COVID-19 Global Rheumatology Alliance physician-reported registry. Ann Rheum Dis 79:859-866. https:// doi.org/10.1136/annrheumdis-2020-217871

97. Sattui SE, Conway R, Putman MS, Seet AM, Gianfrancesco MA, Beins K, Hill C, Liew D, Mackie SL, Mehta P, Neill L, Gomez G, Salinas MIH, Maldonado FN, Mariz HA, de Sousa Studart SA, Araujo NC, Knight A, Rozza D, Quartuccio L, Samson M, Bally S, Maria AT, Chazerain P, Hasseli R, Muller-Ladner U, Hoyer BF, Voll R, Torres RP, Luis M, Ribeirio SLE, Al-Emadi S, Sparks JA, Hsu TY, D’Silva KM, Patel NJ, Wise L, Gilbert E, 
Almada MV, Duarte-Garcia A, Ugarte-Gil M, Jacobsohn L, Izadi Z, Strangfeld A, Mateus EF, Hyrich KL, Gossec L, Carmona L, Lawson-Tovey S, Kearsley-Fleet L, Schaefer M, Sirotich E, Hausmann JS, Sufka P, Bhana S, Liew JW, Grainger R, Machado PM, Wallace ZS, Yazdany J, Robinson PC, Global Rheumatology A (2021) Outcomes of COVID-19 in patients with primary systemic vasculitis or polymyalgia rheumatica from the COVID19 Global Rheumatology Alliance physician registry: a retrospective cohort study. Lancet Rheumatol 3:e855-e864. https:// doi.org/10.1016/S2665-9913(21)00316-7

98. Strangfeld A, Schafer M, Gianfrancesco MA, Lawson-Tovey S, Liew JW, Ljung L, Mateus EF, Richez C, Santos MJ, Schmajuk G, Scire CA, Sirotich E, Sparks JA, Sufka P, Thomas T, Trupin L, Wallace ZS, Al-Adely S, Bachiller-Corral J, Bhana S, Cacoub P, Carmona L, Costello R, Costello W, Gossec L, Grainger R, Hachulla E, Hasseli R, Hausmann JS, Hyrich KL, Izadi Z, Jacobsohn L, Katz P, Kearsley-Fleet L, Robinson PC, Yazdany J, Machado PM, Alliance C-GR (2021) Factors associated with COVID-19-related death in people with rheumatic diseases: results from the COVID-19 Global Rheumatology Alliance physician-reported registry. Ann Rheum Dis 80:930-942. https://doi.org/10.1136/annrheumdis-2020-219498

99. Ghosh J, Kant S, Kastner IV, Geetha D (2021) Bamlanivimab decreases severe outcomes of SARS-CoV-2 infection in ANCA vasculitis patients. Kidney Int Rep. https://doi.org/10.1016/j.ekir. 2021.12.010

100. Floyd L, Elsayed ME, Seibt T, von Bergwelt-Baildon A, Seo P, Antiochos B, Kant S, Morris A, Dhaygude A, Schonermarck U, Geetha D (2021) SARS-CoV-2 vaccine response in ANCA associated vasculitis patients. Kidney Int Rep. https://doi.org/ 10.1016/j.ekir.2021.12.004

101. Kant S, Azar A, Geetha D (2021) Antibody response to COVID-19 booster vaccine in rituximab-treated patients with anti-neutrophil cytoplasmic antibody-associated vasculitis. Kidney Int. https://doi.org/10.1016/j.kint.2021.11.012

102. Machado PM, Lawson-Tovey S, Strangfeld A, Mateus EF, Hyrich KL, Gossec L, Carmona L, Rodrigues A, Raffeiner B, Duarte C, Hachulla E, Veillard E, Strakova E, Burmester GR, Yardimci GK, Gomez-Puerta JA, Zepa J, Kearsley-Fleet L, Trefond L, Cunha M, Mosca M, Cornalba M, Soubrier M, Roux N, Brocq O, Durez P, Conway R, Goulenok T, Bijlsma JW, McInnes IB, Mariette X (2021) Safety of vaccination against SARS-CoV-2 in people with rheumatic and musculoskeletal diseases: results from the EULAR Coronavirus Vaccine (COVAX) physicianreported registry. Ann Rheum Dis. https://doi.org/10.1136/annrh eumdis-2021-221490

103. David R, Hanna P, Lee K, Ritchie A (2022) Relapsed ANCA associated vasculitis following Oxford AstraZeneca ChAdOx1-S COVID-19 vaccination: a case series of two patients. Nephrology (Carlton) 27:109-110. https://doi.org/10.1111/nep.13993

104. Kondo M, Yamanaka K (2021) Possible HSP reactivation postCOVID-19 vaccination and booster. Clin Case Rep 9:e05032. https://doi.org/10.1002/ccr3.5032

105. Dharia T, Venkatachalam S, Baker JF, Banerjee S, Curtis D, Danila MI, Gavigan K, Gordon J, Merkel PA, Shaw DG, Young K, Curtis JR, Nowell WB, George MD (2021) Medication interruptions and subsequent disease flares during the COVID-19 pandemic: a longitudinal online study of patients with rheumatic disease. Arthritis Care Res (Hoboken). https://doi.org/10.1002/ acr. 24837

Publisher's Note Springer Nature remains neutral with regard to jurisdictional claims in published maps and institutional affiliations. 